\title{
Transmission ratio distortion and maternal effects confound the analysis of modulators of cystic fibrosis disease severity on $19 q 13$
}

\author{
Tim Becker ${ }^{1}$, Silke Jansen ${ }^{2}$, Stephanie Tamm ${ }^{2}$, Thomas F Wienker ${ }^{1}$, Burkhard Tümmler ${ }^{2}$ and \\ Frauke Stanke*,2
}

${ }^{1}$ Institute of Medical Biometrics, Informatics and Genetics (IMBIE), University of Bonn, Bonn, Germany; ${ }^{2}$ Department
of Pediatrics, Hannover Medical School, Hannover, Germany

Two entities localised within in a $5 \mathrm{Mb}$ interval on 19q13, that is the transforming growth factor $\beta 1$ (TGF 1 1) and the cystic fibrosis modifier 1, have been reported to modulate disease severity of cystic fibrosis (CF), albeit the designation of the risk allele for TGF 1 differs between studies. We have analysed genotyping data at seven microsatellite loci and four single nucleotide polymorphisms targeting the 19q13 area from 37 nuclear CF families with two affected offspring exhibiting extreme clinical phenotypes for indicators of transmission-ration distortion, maternal genetic or maternal non-genetic effects. Evidence for a transmission-ratio distortion was obtained at D19S112 $(P=0.0304)$ near the recently characterised myotonic dystrophy locus myotonic dystrophy protein kinase (DMPK). Maternal and paternal genotype distributions were significantly different at rs1982073 (Leu10Pro at TGF 1 1) whereby all CF sibs heterozygous at rs1982073 inherited the Leu10 allele from their mother $(P=0.000132)$ in our sibling panel. To ask whether the improved survival in CF over the last decades has any influence on TGF 1 allele frequencies, we analysed unrelated F508del homozygotes who were stratified by birth cohort. Sensitivity with respect to the survivor bias was reflected by significantly higher incidence of mild cystic fibrosis transmembrane conductance regulator mutation genotypes in the early born patient cohort $(P=0.0169)$, and an allelic imbalance was also observed at TGF $\beta 1(P=0.0664)$. In conclusion, the role of TGF 1 as a CF modulator, suggested from studies with a case-control setting, needs to be interpreted with caution unless family-based analysis is carried out to identify parental genetic and non-genetic effects.

European Journal of Human Genetics (2007) 15, 774-778; doi:10.1038/sj.ejhg.5201825; published online 4 April 2007

Keywords: cystic fibrosis; modulator; transmission-ratio distortion; maternal effect; TGF $\beta 1$

Introduction

The variability of the clinical course of cystic fibrosis (CF) suggests that factors other than the disease-causing cystic fibrosis transmembrane conductance regulator (CFTR) gene mutations shape the patients' phenotype. ${ }^{1}$ In addition to

${ }^{*}$ Correspondence: Dr. rer. nat. F Stanke, Department of Pediatrics OE6710, Hannover Medical School, Carl-Neuberg-Strasse 1, 30625 Hannover, Germany.

Tel: + 49511532 6722; Fax: + 49511532 6723;

E-mail: mekus.frauke@mh-hannover.de

Received 1 December 2006; revised 16 February 2007; accepted 21 February 2007; published online 4 April 2007 the well-characterised role of the CFTR mutation genotype and environmental factors, modulating genes are considered in CF by an increasing number of studies. ${ }^{2}$

Two entities on $19 q 13$, that is the gene encoding the transforming growth factor $\beta 1$ (TGF $\beta 1$ ) and the still undetermined gene mapped as cystic fibrosis modifier 1 (CFM1) in 1999, have been implied as modulators on CF pulmonary disease severity ${ }^{3,4}$ and the CF endophenotype meconium ileus. ${ }^{5}$

The European CF Twin and Sibling Study applies the concept of informative patient pairs with extreme clinical phenotypes to identify and map CF modulators. ${ }^{6-8}$ 
Recently, we have reported on the association of D19S197, but not of TGFB1 or the CFM1-related marker D19S112 with the CF disease phenotype. ${ }^{9}$ Here, we have analysed our genotype data for indicators of transmission-ratio distortion, imprinting, maternal genetic or maternal nongenetic effects mediated by elements on 19q13.

\section{Patients and methods}

The European CF twin and sibling study patient panel As described in detail previously, ${ }^{6}$ we have recruited CF twin and sibling pairs and their parents from central Europe. For the identification of CF modulators, F508delCFTR homozygous dizygous patient pairs with concordant mild disease, concordant severe disease and discordant pairs were selected. ${ }^{6}$ In total, 37 nuclear families with contrasting phenotypes were enrolled for genotyping whereby parental DNA was obtained in 32 families. $^{8}$

\section{Unrelated F508del homozygotes stratified for year of birth}

The long-term prognosis and survival has improved considerably over the last decades. In order to ask whether this manifests in the CF population at the typed markers, we have retrospectively recruited CF patients born in 1959-1967 or 1970-1975 who were enrolled for CFTR mutation analysis at the CF clinic in Hannover in 19891994. The CFTR mutation genotype was resolved for 130 patients, allowing to assess the proportions of mild and severe CFTR mutation genotypes by birth cohort. Mild CFTR mutation genotypes, associated with pancreatic sufficiency, better lung function and better survival, ${ }^{10}$ were assigned in accordance with the European Epidemiologic Registry of CF. ${ }^{10}$

The study was approved by the local medical ethics committee. DNA of 21 F508del homozygotes born 19591967 and of 49 patients born 1970-1975 was available or could be rescued by whole genome amplification using the GenomiPhi-System (GE Healthcare).

\section{Genetic markers}

The European CF twins and sibs with extreme clinical phenotypes have been genotyped at seven microsatellites and four single nucleotide polymorphisms (SNPs) on 19q13 (Table 1). SNPs were analysed by PCR/RFLP and microsatellite genotypes were ascertained by direct blotting electrophoresis (GATC, Konstanz) as described elsewhere. ${ }^{11}$ All technical details are specified within the supplement.

To allow the identification of haplotype blocks and correspondingly enable a correction for multiple testing within sets of linked markers, pairwise marker linkage disequilibrium (LD) was judged both on the basis of Lewontins $\mathrm{D}^{\prime}$ measure ${ }^{12}$ as well as on the signicance of the $\chi^{2}$ measure as described in detail previously. ${ }^{9}$ As expected, the two TGF 1 markers rs1982073 and rs1800469 were in LD defining block B (Table 1). Furthermore, two SNPs and two microsatellites spanning a $100000 \mathrm{bp}$ area from rs1126454 to rs4802129 were observed as block $\mathrm{C}$ on the present low-density map.

\section{Data evaluation}

As described in detail elsewhere, ${ }^{9}$ nuclear families were analyzed with the Monte Carlo simulation based association test described by Knapp and Becker, ${ }^{13}$ which can be viewed as an extension of the transmission-disequilibrium test $^{14}$ to both nuclear families with more than one affected child and to haplotypes.

Furthermore, we tested for parent-of-origin effects using the HAP-PAT introduced by Becker et al. ${ }^{15}$ This test considers the parental origin of the alleles of heterozygous affected children. As shown by Weinberg, ${ }^{16}$ this yields a very powerful test for imprinting and assocation. Significant results obtained with the HAP-PAT give evidence either for imprinting effects or for an effect of the maternal genotype on the child's phenotype. To distinguish the two possibilities, we also compared paternal and maternal genotypes using the case-control method described by Becker et al. ${ }^{17}$

All computations, that is the extended transmissiondisequilibrium test, the parental asymmetry test HAP-PAT and the case-control comparisons, were carried out using the FAMHAP software package. ${ }^{18}$

Genotype and allele distribution among unrelated F508del homozygotes stratified for birth cohort were compared by permutation analysis through Monte Carlo simulation. ${ }^{19}$

\section{Results}

Analysis of all nuclear families pooled, irrespective of their phenotype by transmission-disequilibrium test did not yield a significant result at all loci tested, irrespective of whether both parental transmissions or only the paternal transmissions or only the maternal transmissions were taken into account (data not shown). In contrast, the parental origin of alleles was different among heterozygous offspring at TGF $\beta 1$ (block B; $P_{\text {corr }}=0.000145$; Table $1 \mathrm{a}$ and b) and marker D19S112 $(P=0.0304$; Table 1a). Surprisingly, we observed that all heterozygous siblings inherited allele 2 from their mother at rs1982073 (Table 1b). Comparing maternal and paternal genotype frequencies, a significant difference was observed at TGF $\beta 1$ (block B; $P_{\text {corr }}=0.0339$; Table 1a and c).

To ask whether the improved survival in CF over the last decades has any influence on TGF $\beta 1$ allele frequencies, we analysed unrelated F508del homozygotes from the CF clinic in Hannover who were stratified by birth cohort. Sensitivity with respect to the survivor bias is reflected by significantly higher incidence of mild CFTR mutation 
Table 1a Comparison of parental origin of alleles in heterozygous offspring and parental genotype frequencies in 37 F508del homozygous CF sib pair families

\begin{tabular}{|c|c|c|c|c|c|c|}
\hline \multirow[b]{2}{*}{ Marker } & \multirow[b]{2}{*}{$\begin{array}{l}\text { Position on } \\
\text { Chr19 }\end{array}$} & \multirow[b]{2}{*}{ Block } & \multicolumn{2}{|c|}{ Parental asymmetry test HAP-PAT a } & \multicolumn{2}{|c|}{ Comparison of maternal and paternal genotypes $b$} \\
\hline & & & $\begin{array}{l}\text { Uncorrected single } \\
\text { locus P-value }\end{array}$ & $\begin{array}{c}\text { Corrected P-value for } \\
\text { block }\end{array}$ & $\begin{array}{l}\text { Uncorrected single } \\
\text { locus P-value }\end{array}$ & $\begin{array}{l}\text { Corrected P-value for } \\
\text { block }\end{array}$ \\
\hline rs1982073 & 46550761 & $\mathrm{~B}$ & 0.000132 & 0.000145 & 0.0123 & 0.0339 \\
\hline rs1800469 & 46552136 & B & 0.0325 & & 0.3326 & \\
\hline rs1126454 & 46824154 & C & 0.1855 & 0.4444 & 0.1546 & 0.3531 \\
\hline D19S197 & 46824244 & $\mathrm{C}$ & 0.3343 & & 0.6772 & \\
\hline CCSat3 & 47305349 & $\mathrm{D}$ & 0.2489 & 0.2489 & 0.3324 & 0.3324 \\
\hline CCSat6 & 47793292 & $E$ & 0.2341 & 0.2341 & 0.4749 & 0.4749 \\
\hline PSGSat & 48499978 & $\mathrm{~F}$ & 0.7368 & 0.7368 & 0.3354 & 0.3354 \\
\hline D19S112 & 51070821 & G & 0.0304 & 0.0304 & 0.1487 & 0.1487 \\
\hline
\end{tabular}

${ }^{a}$ The parental asymmetry test HAP-PAT analyzes the origin of alleles in nuclear families with heterozygous offspring. Primary genotyping data for rs1982073 is given in Table $1 \mathrm{~b}$.

bPrimary data for rs1982073 is given in Table 1c.

'SNP rs 1982073 corresponds to the mis-sense variant Leu10Pro in TGFB1.

Table 1b Asymmetry of parental transmissions to heterozygous CF siblings at rs 1982073

\begin{tabular}{|c|c|c|c|c|}
\hline & $\begin{array}{c}\text { Total no. of families } \\
\text { with heterozygous } \\
\text { offspring }\end{array}$ & $\begin{array}{c}\text { No. of families with } \\
\text { one heterozygous } \\
\text { sibling }\end{array}$ & $\begin{array}{c}\text { No. of families with } \\
\text { two heterozygous } \\
\text { siblings }\end{array}$ & $\begin{array}{l}\text { Total number of } \\
\text { heterozygous } \\
\text { siblings }\end{array}$ \\
\hline $\begin{array}{l}\text { Observed maternal transmissions of allele } 2^{\mathrm{a}} \text { at } \\
\text { rs } 1982073\end{array}$ & 15 & 9 & $6^{b}$ & 21 \\
\hline $\begin{array}{l}\text { Observed paternal transmissions of allele } 2^{\mathrm{a}} \text { at } \\
\text { rs } 1982073\end{array}$ & 0 & 0 & 0 & 0 \\
\hline $\begin{array}{l}\text { Non-informative phase or no parental DNA } \\
\text { available }\end{array}$ & 6 & $1^{c}$ & $5^{d}$ & 11 \\
\hline Total & $21^{\mathrm{e}}$ & 10 & 11 & 32 \\
\hline
\end{tabular}

ars1982073 allele 2, denoting the presence of restriction site for BstAPI as assessed by PCR-RFLP test, corresponds to Leu10 in TGF 1.

${ }^{\mathrm{b}}$ The maternal transmission of allele 2 was observed for 12 siblings in these six families.

${ }^{C}$ For this family, DNA was available for one parent only who carries the heterozygous genotype.

${ }^{d}$ For three of these families, no parental DNA was available. In one family, both parents are heterozygous and in one family, DNA was available for one parent only who carries the heterozygous genotype.

e Out of the 37 families, 16 sib pairs were homozygous at rs 1982073 who are not considered by the parental asymmetry test. ${ }^{15,16}$

Table 1c Parental genotype distribution at rs1982073

\begin{tabular}{|c|c|c|}
\hline & $\begin{array}{c}\text { Father } n \\
\text { (frequency) }\end{array}$ & $\begin{array}{c}\text { Mother } n \\
\text { (frequency) }\end{array}$ \\
\hline \multicolumn{3}{|l|}{ Genotype at rs1982073 ${ }^{a}$} \\
\hline $1-1$ & 9 & 4 \\
\hline $1-2$ & 14 & 10 \\
\hline $2-2$ & 5 & 15 \\
\hline \multirow{2}{*}{\multicolumn{3}{|c|}{$\begin{array}{l}\text { Iotal: } \\
\text { Alleles at rs } 1982073^{a}\end{array}$}} \\
\hline & & \\
\hline 1 & $32(0.57)$ & $18(0.31)$ \\
\hline 2 & $24(0.43)$ & $40(0.69)$ \\
\hline
\end{tabular}

${ }^{a} 1982073$ allele 2, denoting presence of restriction site for BstAPI as assessed by PCR-RFLP test, corresponds to Leu10 in TGF 1 .

genotypes in the early born patient cohort $(P=0.0169$; Table 2a). Among the subsets of F508del homozygous patients from these birth cohorts, allele frequencies at rs1982073 were dissimilar $(P=0.0664$; Table $2 b)$.

\section{Discussion}

$T G F \beta 1$, displaying a leucine to proline exchange at codon 10 in the human population, has been identified as a modifier among F508del-CFTR homozygotes by two independent studies. ${ }^{3,4}$ However, the authors disagree on the designation of the risk allele. Arkwright et $a l^{3}$ describe the TGF 1 variant Leu10 as a risk allele for accelerated decline of pulmonary function with age among 171 CF patients from the North West region of the United Kingdom. In contrast, Drumm et $a l^{20}$ have reported an elevated frequency of Pro10 TGF $\beta 1$ alleles among more than 800 patients with a severe pulmonary phenotype recruited from 44 North American CF clinics, indicating that the TGF $\beta 1$ risk allele is Pro10 in their patient panel. In conclusion, the data concerning the role of TGF 1 in CF is at best contradictory at the moment even though the functional consequences of Pro10, resulting in lower circulating levels 
of the anti-inflammatory cytokine in serum, are well characterised.

The failure to replicate a finding in an association study can be explained by numerous reasons whereby falsenegative results are usually attributed to a lack of power of one study. Sadly, this frequently quoted argument ignores the prerequisite for assuming two similar outcomes, namely that the two patient populations under study

Table 2a Distribution of mild and severe CFTR mutation genotypes among two CF cohorts recruited in the early $1990 \mathrm{~s}$ and stratified for contrasting year of birth

\begin{tabular}{llc}
\hline Birth cohort & $\begin{array}{l}\text { CFTR mutation } \\
\text { genotype }\end{array}$ & $\begin{array}{c}\text { No. of patients } \\
\text { (frequency) }\end{array}$ \\
\hline $1959-1967$ & Severe $^{\mathrm{a}}$ & $37(84 \%)$ \\
& Mild $^{\mathrm{b}}$ & $7(16 \%)$ \\
$1970-1975$ & Severe $^{\mathrm{a}}$ & $83(97 \%)$ \\
& Mild $^{\mathrm{b}}$ & $3(3 \%)$ \\
\hline
\end{tabular}

Patients carry two severe CFTR mutations according to the classification by the European Epidemiologic Registry of Cystic Fibrosis. ${ }^{10}$

Patients carry one mild CFTR mutation according to the classification by the European Epidemiologic Registry of Cystic Fibrosis. ${ }^{10}$

${ }^{a, b}$ Comparison of observed number of mild and severe genotypes: $P=0.0169$. are comparable. In the context of CF, the continuously changing symptomatic treatment and its consequences on manifestation of disease and improvement of survival will jeopardise any attempts to identify clinically relevant genetic modifiers, unless one thoroughly controls during recruitment of the study cohort for any bias of patient history introduced by date of birth and the previous quality of care. Such a confounding survivor effect is suggested by findings on the Leu10Pro polymorphism (rs1982073) in TGF 1 in our local CF population (see Table 2b).

In our set of European F508del homozygous CF twins and siblings, comparing concordant mildly and concordant severely affected sib pairs from matched birth cohorts, ${ }^{8}$ no association of TGF 11 markers with disease severity was observed. ${ }^{9}$ However, maternal and paternal genotype distributions were significantly different at rs1982073 (Leu10Pro at TGF 1 1) whereby homozygosity for allele Leu10 was elevated among maternal genotypes and all CF sibs heterozygous at rs1982073 inherited the Leu10 allele from their mother $(P=0.000132$, Table 1$)$, demonstrating that maternal effects outweigh the inherited genetic predisposition at TGF $\beta 1$. In other words, the influence of the maternal genotype - as outlined below,

Table 2b Allele distribution at rs1982073 among unrelated F508del homozygotes from contrasting birth cohorts

\begin{tabular}{|c|c|c|c|c|}
\hline Birth cohort & CFTR mutation genotype & No. of patients ${ }^{b}$ & $\begin{array}{c}r s 1982073^{\mathrm{a}} \\
\text { Allele } 1^{\mathrm{c}} n \text { (frequency) }\end{array}$ & Allele $2^{\mathrm{d}} n$ (frequency) \\
\hline $\begin{array}{l}1959-1967 \\
1970-1975\end{array}$ & $\begin{array}{l}\text { F508del/F508del } \\
\text { F508del/F508del }\end{array}$ & $\begin{array}{l}21 \\
49\end{array}$ & $\begin{array}{r}7(0.17) \\
32(0.33)\end{array}$ & $\begin{array}{l}35(0.83) \\
66(0.67)\end{array}$ \\
\hline
\end{tabular}

${ }^{a}$ Comparison of allele distribution at rs1982073: $P=0.0664$.

${ }^{b}$ Subset of patients with severe CFTR mutation genotype from Table 2a.

crs1982073 allele 1, denoting the absence of restriction site for BstAPI as assessed by PCR-RFLP test, corresponds to Pro10 in TGF $\beta 1$.

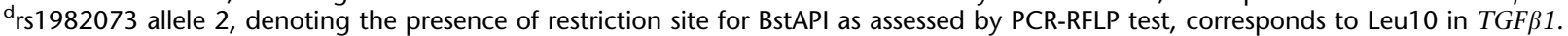

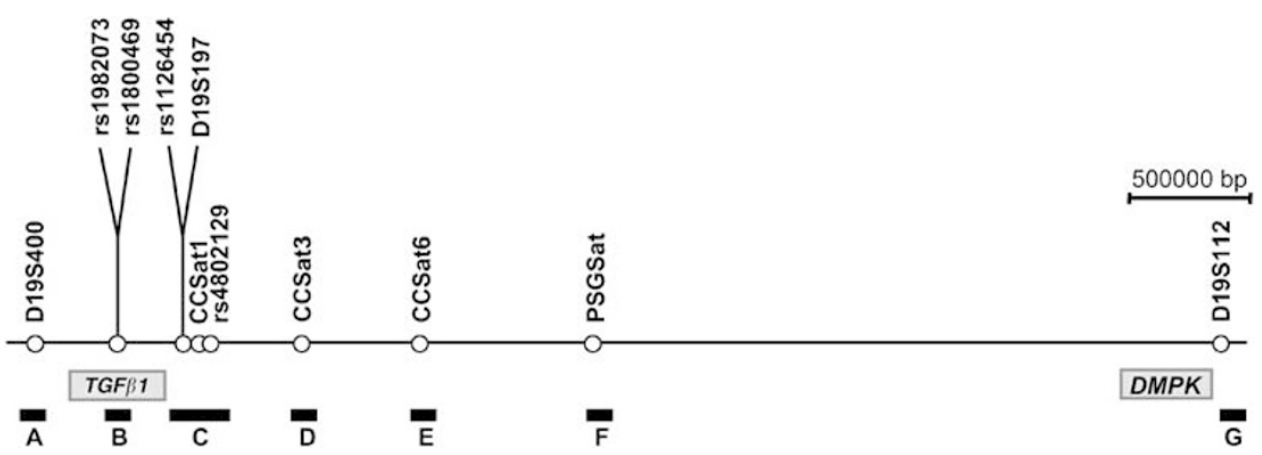

Figure 1 Physical map of the analysed area on 19q13. The map is drawn to scale representing physical distances on NT_011109 for markers D19S400, rs1982073/rs1800469, rs1126454/D19S197, CCSat1, rs4802129, CCSat3, CCSat6 and PSCSat and D19S112. The distance between the two TGFB1 SNPs rs 1982073 (Leu10Pro) and rs1800469 (C-509 T) is 1375 bp. The SNP rs1126454 is localised in a distance of 90 bp to the microsatellite D19S197. The position of TGF $\beta 1$, published as a CF modulator by Arkwright $e$ t $\left.a\right|^{3}$ and by Drumm et al ${ }^{4}$ with incompatible results with respect to the designation of the risk allele, is indicated below the physical map. DMPK is the myotonic dystrophy locus for which Dean et $a^{21}$ have described a transmission ratio distortion in human preimplantation embryos. For the sake of clarity, the genes TGF 1 and DMPK1 are not drawn to scale. D19S112, reported to detect the cystic fibrosis modulator 1 by Zielenski et $a f^{5}$, is located in a distance of $100 \mathrm{~kb}$ to DMPK. Capital letters below the bold bars correspond to the haplotype blocks reported upon in Table 1 a. 
presumably mediated by TGF $\beta 1$ supply to the offspring in human milk in early postnatal life - exceeds the life-long effect of variants of the anti-inflammatory, albeit profibrotic cytokine mediated by the child's genotype itself. Moreover, evidence for a transmission-ratio distortion at D19S112 was observed ( $P=0.0304$, Table 1$)$, presumably mediated by the myotonic dystrophy locus DMPK which is located $100000 \mathrm{bp}$ upstream of D19S112. A transmissionratio distortion manifesting in human preimplantion embryos has recently been described for DMPK. ${ }^{21}$

Maternal TGF $\beta 1$, the major anti-inflammatory cytokine in human milk provided by breast-feeding to the infant, is known to protect against gut inflammation ${ }^{22}$ and infant wheezing. ${ }^{23}$ Long-term exclusive breast feeding was shown to attenuate disease severity in $\mathrm{CF}^{24}$ and consequently, the impact of maternal TGF $\beta 1$ in CF may be more prominent in patients with late diagnosis and/or delayed onset of therapeutic intervention. In this context, the interplay between exogenous maternal supply and endogenous production of TGF $\beta 1$ may deserve further investigation.

The CF modulator indicated by the previously described transmission disequilibrium among discordant pairs at D19S $197^{9}$ was confirmed with the present marker set as mildly and severely affected CF sib pairs displayed different allele distributions at rs4802129 $(P=0.0161$; for uncorrected single locus; data not shown), indicating that the block $\mathrm{C}$, encompassing the CEACAM gene cluster, harbours a genetic variant that shapes the clinical course of $\mathrm{CF}$. Although the identity of the modulator cannot be resolved on our current low-density map, further investigation and high-resolution fine mapping of block $\mathrm{C}$ among CF twins and sibs is underway to identify the genetic entity on 19q13 that has an impact on CF disease severity (Figure 1).

\section{Acknowledgements}

Supported by the Deutsche Forschungsgemeinschaft (SFB621, C7).

\section{References}

1 Dorfman R, Zielenski J: Genotype-Phenotype correlations in cystic fibrosis. Prog Respir Res 2006; 34: 61-68.

2 Cutting GR: Modifier genetics: cystic fibrosis. Anпu Rev Genomics Hum Genet 2005; 6: 237-260.

3 Arkwright PD, Laurie S, Super M et al: TGF-beta(1) genotype and accelerated decline in lung function of patients with cystic fibrosis. Thorax 2000; 55: 459-462.

4 Drumm ML, Konstan MW, Schluchter MD et al: Genetic modifiers of lung disease in cystic fibrosis. N Engl J Med 2005; 353: $1443-1453$.
5 Zielenski J, Corey M, Rozmahel R et al: Detection of a cystic fibrosis modifier locus for meconium ileus on human chromosome 19q13. Nat Genet 1999; 22: 128-129.

6 Mekus F, Ballmann M, Bronsveld I, Bijman J, Veeze H, Tümmler B: Categories of deltaF508 homozygous cystic fibrosis twin and sibling pairs with distinct phenotypic characteristics. Twin Res 2000; 3: 277-293.

7 Mekus F, Laabs U, Veeze H, Tümmler B: Genes in the vicinity of CFTR modulate the cystic fibrosis phenotype in highly concordant or discordant F508del homozygous sib pairs. Hum Genet 2003; 112: 1-11.

8 Stanke F, Becker T, Cuppens $\mathrm{H}$ et al: The TNFalpha receptor TNFRSF1A and genes encoding the amiloride-sensitive sodium channel ENaC as modulators in cystic fibrosis. Hum Genet 2006; 119: $331-343$.

9 Stanke F, Becker T, Tümmler B: Genetic modifiers in cystic fibrosis. N Engl J Med 2006; 354: 88-90.

10 Koch C, Cuppens H, Rainisio M et al: European Epidemiologic Registry of Cystic Fibrosis (ERCF): comparison of major disease manifestations between patients with different classes of mutations. Pediatr Pulmonol 2001; 31: 1-12.

11 Mekus F, Dörk T, Deufel T, Morral N, Tümmler B: Analysis of microsatellites by direct blotting electrophoresis and chemiluminescence detection. Electrophoresis 1995; 16: 1886-1888.

12 Lewontin RC: The interaction of selection and linkage. I. General considerations; heterotic models. Genetics 1964; 49: 49-67.

13 Knapp M, Becker T: Family-based association analysis with tightly linked markers. Hum Hered 2003; 56: 2-9.

14 Spielman RS, McGinnis RE, Ewens WJ: Transmission test for linkage disequilibrium: the insulin gene region and insulindependent diabetes mellitus (IDDM). Am J Hum Genet 1993; 52: 506-516.

15 Becker T, Baur MP, Knapp M: Detection of parent-of-origin effects in nuclear families using haplotype analysis. Hum Hered 2006; 62: $64-76$.

16 Weinberg CR: Methods for detection of parent-of-origin effects in genetic studies of case-parents triads. Am J Hum Genet 1999; 65: 229-235.

17 Becker T, Cichon S, Jonson E, Knapp M: Multiple testing in the context of haplotype analysis revisited: application to casecontrol data. Ann Hum Genet 2005; 69: 747-756.

18 Becker T, Knapp M: Maximum-likelihood estimation of haplotype frequencies in nuclear families. Genet Epidemiol 2004; 27: $21-32$.

19 Sham PC, Curtis D: Monte Carlo Tests for associations between disease and alleles at highly polymorphic loci. Ann Hum Genet 1995; 59: 97-105.

20 Grainger DJ, Heathcote K, Chiano M et al: Genetic control of the circulating concentration of transforming growth factor type beta1. Hum Mol Genet 1999; 8: 93-97.

21 Dean NL, Loredo-Osti JC, Fujiwara TM et al: Transmission ratio distortion in the myotonic dystrophy locus in human preimplantation embryos. Eur J Hum Genet 2006; 14: 299-306.

22 Claud EC, Savidge T, Walker WA: Modulation of human intestinal epithelial cell IL-8 secretion by human milk factors. Pediatr Res 2003; 53: 419-425.

23 Oddy WH, Halonen M, Martinez FD et al: TGF-beta in human milk is associated with wheeze in infancy. J Allergy Clin Immunol 2003; 112: 723-728.

24 Parker EM, O'Sullivan BP, Shea JC, Regan MM, Freedman SD: Survey of breast-feeding practices and outcomes in the cystic fibrosis population. Pediatr Pulmonol 2004; 37: 362-367. 